\title{
Osteosynthesis of Intercondylar Humerus Fracture Using Bryan and Morrey Approach
}

Lakhey S, 'Sharma S, ${ }^{2}$ Pradhan RL, ${ }^{1}$ Pandey BK, ${ }^{1}$ Manandhar RR, ${ }^{1}$ Rijal KP'

'Department of Orthopaedics, Kathmandu Medical College Teaching Hospital, Sinamangal, Kathmandu, Nepal.

\section{ABSTRACT}

Introduction: The Olecranon approach has been the gold standard approach to fix fractures of distal articular surface of Humerus. Although it provides good exposure, it might result in delayed union, non-union and implant related complications at the osteotomy site. The aim of this study was to determine the functional outcome of displaced intra-articular distal humerus fracture fixation using an alternative approach: the Bryan and Morrey approach.

Methods: Twenty patients with twenty AO type $C_{1}$ and $C_{2}$ intercondylar fractures of the distal humerus had bicolumnar fixation of the distal humerus with two contoured reconstruction plates and screws on the dorsal surface or various combinations of a single reconstruction plate, screws and K-wires using a Bryan and Morrey approach. All patients were followed up for 12 months post operatively. The union time, condition of the joint and any complications were noted.

Results: All twenty fractures had united at four months follow-up. The mean fixed flexion deformity was $9.0^{\circ}$ (range $0^{\circ}-15^{\circ}$ ) and the mean arc of motion was $115.0^{\circ}$ (range $85^{\circ}-130^{\circ}$ ). All patients had grade 4 triceps strength and stable elbows at the end of 12 months follow up. One patient had deep seated wound infection resulting in necrosis of the triceps tendon requiring a second operative procedure.

Conclusions: Bryan and Morrey approach is a simpler, easier and better approach as compared to the other posterior approaches to the elbow joint, and therefore, can be used as the approach of choice to fix fractures of the distal articular surface of Humerus.

Key Words: fracture, Humerus, intercondylar, osteosynthesis

Correspondence:

Dr. Shishir Lakhey

Department of Orthopaedics

Kathmandu Medical College Teaching Hospital

Sinamangal, Kathmandu, Nepal.

Email: slakhey64@yahoo.com

Phone: 9851005921 


\section{INTRODUCTION}

Distal articular Humerus fractures are preferably treated by open reduction and internal fixation. ${ }^{1}$ The surgery is technically demanding and an adequate exposure of the distal Humerus articular surface is required. The olecranon approach has been the gold standard surgical approach to fix such fractures. ${ }^{1-3}$ It is the most commonly used surgical approach and provides good visualization of the fracture. ${ }^{4}$ However, delayed union and non-union at the osteotomy site and implant related complications at the osteotomy site are its potential disadvantages..$^{5-8}$ An alternative approach, the Bryan and Morrey approach ${ }^{4}$ avoids the olecranon osteotomy while providing adequate exposure at the same time. Thus, the aim of this study is to determine the functional outcome of displaced intraarticular distal humerus fracture fixation using Bryan and Morrey approach.

\section{METHODS}

An interventional study was conducted in the Department of Orthopaedics, Kathmandu Medical College Hospital involving 20 patients with intercondylar fracture of the Humerus from July 2006 to June 2009. Ethical approval and patient consent was taken.

The study participants were those with $A O$ type $C_{1}$ and $\mathrm{C}_{2}$ intercondylar fractures of the distal Humerus. They were selected on convenience sampling. There was also one patient with grade 1 compound fracture. Elbows with previous bony pathologies or injuries were excluded from the study. The selected ones underwent internal fixation using Bryan and Morrey approach.

All the operations were done under brachial plexus block supplemented with/without general anesthesia. All the patients were put in the lateral position and a pneumatic tourniquet was applied in the upper arm. The arm was rested on pillows with the elbow flexed at $90^{\circ}-100^{\circ}$.

A straight incision was made lateral to the olecranon tip. Medial and lateral flaps were raised to expose the supracondylar ridges on either side of the distal humerus. The ulnar nerve was isolated, dissected free from behind the medial epicondyle distally around $7 \mathrm{~cm}$ taking care to preserve the branches to flexor carpi ulnaris and kept away from the operating field with an infant feeding tube. The triceps was reflected off the posterior surface of the humerus from the medial side by blunt and sharp dissection and reflected laterally along with the capsule. The triceps tendon at the olecranon tip was dissected off by electro-cautery. The dissection was continued distally $8-10 \mathrm{~cm}$ erasing the ulnar attachment of the anconeus and the periosteum distal to it such that the triceps tendon, anconeus and periosteum formed one continuous sleeve of tissue from the triceps attachment in the olecranon tip to the periosteum 8-10 distally.

The intra-articular component was reduced and fixed with $4.0 \mathrm{~mm}$ partially threaded cancellous screw and the reconstituted condylar block provisionally fixed to the medial and lateral columns with $1.8 \mathrm{~mm} \mathrm{~K}$ wires. Two $3.5 \mathrm{~mm}$ reconstruction plates were contoured to fit both columns on the dorsal surface of the humerus and fixed with screws in fifteen of twenty cases. In four cases, the reconstituted condylar block was fixed to the medial and lateral columns with a combination of a contoured $3.5 \mathrm{~mm}$ reconstruction plate and screws in one of the columns on the dorsal surface and various combinations of a semi-tubular plate, screws and 2.0 $\mathrm{mm}$ Kirschner wires. The triceps and anconeus were reattached to its original attachment by interrupted no. 1 vicryl sutures placed through previously drilled three to four transverse holes in the proximal Ulna made by a $1.8 \mathrm{~mm} \mathrm{~K}$ wire. The ulnar nerve in all cases was transposed anteriorly in the intramuscular plane. A suction drain was put deep to the triceps and the wound closed in layers.

Post-operatively, the drain was removed in 48-72 hours and passive range of motion exercise was started under the supervision of a physiotherapist. Active assisted elbow movement was started after one month and active elbow movements started after two months. The patient remained in follow up of the physiotherapist for four to six months for increasing the elbow range of motion. Anteroposterior and lateral $\mathrm{X}$-rays were taken at the end of $1,2,3,4,6$ and 12 months follow up. Fracture union was defined as presence of bridging callus across fracture site and/or absence of fracture line on antero-posterior and lateral radiographs. ${ }^{7,9}$ The range of motion was noted in each visit and the strength of the triceps was noted at the end of 6 and 12 months and graded according to the MRC grading..$^{10}$ Elbow stability was examined in the antero-posterior and medio-lateral planes at the end of 6 and 12 months. At the end of 12 months, they were asked about difficulty in performing their activities of daily living and pain experience in their day to day lives.

The statistical analysis was done with statistical package for social sciences version 14 for windows.

\section{RESULTS}

Twelve of the patients were male and eight were female. The average age of the patients was 44.8 years. Eleven patients had sustained the injury as a result of fall and nine of the patients had sustained it in road traffic accidents. Right elbow was involved in fifteen patients and left in five. All patients were followed up for 12 months post operatively. 
All twenty fractures united at four months follow-up. No patient had loss of supination/pronation although all patients had some degree loss of flexion/extension as compared to the normal side. The mean fixed flexion deformity (FFD) was $9.0^{\circ}$ (range $0^{\circ}-15^{\circ}$ ), flexion was $124.0^{\circ}$ (range $90^{\circ}-135^{\circ}$ ) and the mean arc of motion was $115.0^{\circ}$ (range $85^{\circ}-130^{\circ}$ ). All of the patients had grade 4 triceps and elbow flexion strength. All of the patients had stable elbows in the antero-posterior and medio- lateral planes at the end of 12 months follow up. Eighteen of the twenty patients could carry out their activities of daily living unaided and comfortably at the end of 12 months. Two of the patients who could achieve only $100^{\circ}$ of flexion had slight difficulty while eating as the right elbow was involved in both of them. Although, there was slight discomfort, none of the patients experienced pain requiring analgesics.

\section{Table 1. Patient profile}

\begin{tabular}{|c|c|c|c|c|c|c|c|}
\hline SN & Age (years) & Sex* & Side $†$ & Mechanism & $\begin{array}{l}\text { FFD } \\
\text { (in degrees) }\end{array}$ & $\begin{array}{l}\text { Flexion } \\
\text { (in degrees) }\end{array}$ & $\begin{array}{l}\text { Arc of Motion } \\
\text { (in degrees) }\end{array}$ \\
\hline 1. & 57 & $F$ & $\mathrm{R}$ & RTA $\ddagger$ & 10 & 135 & 125 \\
\hline 2. & 60 & $M$ & $\mathrm{R}$ & Fall & 15 & 135 & 120 \\
\hline 3. & 54 & M & $\mathrm{R}$ & Fall & 5 & 135 & 130 \\
\hline 4. & 58 & $\mathrm{~F}$ & $\mathrm{R}$ & RTA & 15 & 130 & 115 \\
\hline 5. & 35 & $M$ & $\mathrm{R}$ & RTA & 10 & 130 & 120 \\
\hline 6. & 31 & $M$ & L & RTA & 5 & 90 & 85 \\
\hline 7. & 22 & $F$ & $\mathrm{R}$ & RTA & 15 & 100 & 85 \\
\hline 8. & 42 & $M$ & $\mathrm{R}$ & Fall & 5 & 125 & 120 \\
\hline 9. & 38 & $\mathrm{~F}$ & L & Fall & 15 & 110 & 95 \\
\hline 10. & 52 & M & $\mathrm{R}$ & Fall & 0 & 130 & 130 \\
\hline 11. & 28 & M & L & RTA & 10 & 130 & 120 \\
\hline 12. & 63 & $\mathrm{~F}$ & $\mathrm{R}$ & Fall & 0 & 100 & 100 \\
\hline 13. & 34 & M & L & Fall & 5 & 115 & 110 \\
\hline 14. & 42 & M & $\mathrm{R}$ & Fall & 10 & 120 & 110 \\
\hline 15. & 49 & M & $L$ & RTA & 10 & 135 & 125 \\
\hline 16. & 46 & $F$ & $\mathrm{R}$ & Fall & 10 & 130 & 120 \\
\hline 17. & 50 & $M$ & $\mathrm{R}$ & Fall & 10 & 125 & 115 \\
\hline 18. & 56 & $\mathrm{~F}$ & $\mathrm{R}$ & RTA & 10 & 135 & 125 \\
\hline 19. & 49 & $M$ & $\mathrm{R}$ & Fall & 10 & 135 & 125 \\
\hline 20. & 30 & $F$ & $\mathrm{R}$ & RTA & 10 & 135 & 125 \\
\hline
\end{tabular}

${ }^{*} \mathrm{M}$ is male, $\mathrm{F}$ is female

$\dagger R$ is right side, $L$ is left side

$\ddagger R T A$ is road traffic accident

One patient developed superficial infection which subsided with oral antibiotics and dressings. Another patient developed deep seated wound infection resulting in necrosis of the triceps tendon requiring a second operative procedure: brachioradialis rotation flap with split skin graft. Her elbow range of motion at the end of 12 months follow up was $15^{\circ}-100^{\circ}$. Since it involved her right elbow, she had slight difficulty in eating with her right hand. The patient with grade 1 compound fracture developed reflex sympathetic dystrophy which resolved with conservative treatment. This patient also developed a small bone block anteriorly at the fracture site due to which her elbow range of motion was $0^{\circ}-100^{\circ}$, and she too had slight difficulty in eating as it involved her right elbow. Four patients developed tingling sensation in the Ulnar nerve distribution post-operatively which resolved at one month follow-up.

\section{DISCUSSION}

The front door to the elbow is at the back. Triceps splitting, Triceps reflecting and olecranon osteotomy are the common posterior approaches to the elbow and olecranon osteotomy is considered the gold standard among the posterior approaches to the elbow. Triceps splitting approach results in triceps weakness due to resultant fibrosis and injury to intermuscular nerve branches. ${ }^{11}$ Since dissection in Bryan and Morrey and Triceps reflecting anconeus pedicle (TRAP) approaches are in the internervous plane, the above-mentioned problem does not occur. Olecranon osteotomy provides a good exposure of the fracture site for distal humerus fracture fixation. However, it is not without its potential disadvantages of delayed union, non-union and other implant related complications. Tension band wiring of 
the olecranon have been associated with various complications. Macko et al reported elbow symptoms due to prominent $\mathrm{k}$-wires in $75 \%$ of their 20 cases and skin breakdown in $20 \%$ cases. ${ }^{12}$ Horne et al reported $75 \%$ of their 88 cases requiring wire removal within a year because of pain and $7 \%$ had non-union. ${ }^{13}$ Ring et al reported a non-union rate of $30 \%$ of transverse olecranon osteotomy in distal Humerus fracture fixation. ${ }^{14}$ Gainor et al observed that $27 \%$ of their patients required hardware removal because of symptoms related to wires and septic olecranon bursitis. ${ }^{15}$ One of the complications of olecranon osteotomy is denervation of anconeus muscle, which provides dynamic stability to the lateral side of the elbow by preventing varus and posterolateral rotatory instability. ${ }^{16}$ Since both TRAP and Bryan and Morrey approaches are anconeus preserving approaches, they do not have this complication. Thus, both TRAP and Bryan and Morrey approaches are safe and are extensile enough to expose and fix complex distal humerus fractures. The Bryan and Morrey approach is simpler and easier than the TRAP approach described by O'Driscoll et al. The triceps and anconeus reattachment is strong enough to start early mobilisation. The range of motion in our study at an average of $115^{\circ}$ (range $85^{\circ}-130^{\circ}$ ) is comparable to the results obtained by various other authors. Ozer et $\mathrm{al}^{17}$ had an average of $116^{\circ}$ (range $95^{\circ}$ $140^{\circ}$ ) for $\mathrm{C} 1$ and $\mathrm{C} 2$ fractures using TRAP approach. Amite et $\mathrm{al}^{7}$ had an average of $118.4^{\circ}$ (range $80^{\circ}-130^{\circ}$ )

\section{REFERENCES}

1. Muller ME, Allgower M, Schneider R. Manual of internal fixation. Techniques recommended by AO Group. $2^{\text {nd }}$ ed. New York: Springer; 1979. p. 71-87.

2. Jupiter JB, Neff U, Holzach P, Allgower M. Intercondylar fractures of the Humerus. An operative approach. JBJS. 1985;67A:226-39.

3. Zagorski JB, Jennings JJ, Burkhalter WE, Uribe JW. Comminuted Intraarticular fractures of the distal Humeral condyles. Surgical vs. Non-surgical treatment. Clin. Orthop. 1986;202:197-204.

4. Bryan RS, Morrey BF. Extensive posterior exposure of the elbow. Clin Orthop Rel Res. 1982;166:188-92.

5. O'Driscoll SW. The Triceps reflecting Anconeus pedicle (TRAP) approach for distal Humeral fractures and nonunions. OCNA. 2000;31:91-101.

6. Coles CP, Barei DP, Nork SE, Taitsman LA, Hanel DP, Bradford HM. The Olecranon Osteotomy: A six-year experience in the treatment of Intraarticular fractures of the distal Humerus. J Orthop Trauma. 2006 Mar;20(3):164-71.

7. Pankaj A, Mallinath G, Malhotra R, Bhan S. Surgical management of intercondylar fractures of the Humerus using triceps reflecting anconeus pedicle (TRAP) approach. Indian J Orthop. 2007;41(3):219-23.

8. Bass RL, Stern PJ. Elbow and forearm anatomy and surgical approaches. Hand Clin. 1994;10:343-56.

9. McKee MD, Wilson TL, Winston L, Schemitsch EH, Richards RR. Functional Outcome following surgical treatment of intraarticular distal Humeral fractures through a posterior approach. JBJS Am. 2000;82(12):1701-7. for C1, C2 and C3 fractures using TRAP approach and Aslam and Willet ${ }^{18}$ achieved an average of $112^{\circ}$ (range $85^{\circ}-122^{\circ}$ ) by olecranon approach. McKee et $\mathrm{al}^{9}$ achieved an average of $108^{\circ}$ (range $55^{\circ}-140^{\circ}$ ) by olecranon and triceps splitting approaches for C1, C2 and C3 fracture. All our patients had grade 4 muscle power of triceps and elbow flexors at the end of 12 months follow up. This differs from the results of TRAP approach of Amite et al $^{7}$ who reported normal triceps strength in $87.5 \%$ of their patients and Ozer et $\mathrm{al}^{17}$ who reported no significant triceps weakness or dysfunction. McKee et $\mathrm{al}^{9}$ too reported around $25 \%$ loss of flexor and extensor strength of the elbow using either olecranon or triceps splitting approach. Eighteen of our twenty patients could carry out their activities of daily living comfortably. Two of the patients who had flexion range of $100^{\circ}$ in their right elbow had slight difficulty while eating, although they could carry out their other activities of daily living comfortably. Although, there was slight discomfort in the elbow, none of the patients experienced pain requiring analgesics.

\section{CONCLUSIONS}

Bryan and Morrey approach is a simpler, easier and better approach as compared to other posterior approaches to the elbow joint, and therefore, can be used as the approach of choice for fixation of fractures of the distal articular surface of Humerus.

10. Connolly P, Yuan HA. Cervical spine fractures. In: White AH, editor. Spine care: diagnosis and conservative treatment. St Louis: Mosby; 1995.

11. Kasser JR, Richards K, Millis M. The triceps-dividing approach to open reduction of complex distal humerus fractures in adolescents: A Cybex evaluation of triceps function and motion. J Pediatr Orthop. 1990;10:93-6.

12. Macko D, Szabo RM. Complications of tension band wiring of olecranon fractures. JBJS Am. 1985;67:1396-401.

13. Horne JG, Tanzer TL. Olecranon fractures: A review of 100 cases. J Trauma. 1981;21:469-72.

14. Ring D, Gullota L, Chin K, Jupiter JB. Olecranon osteotomy for exposures of fractures and nonunions of distal Humerus. J Orthop Trauma. 2004;18:446-9.

15. Gainor BJ, Moussa F, Schott T. Healing rate of transverse osteotomies of the olecranon used in reconstruction of distal humerus fractures. J south Orthop Assoc. 1995;4:263-8.

16. Athwal GS, Rispoli DM, Steinmann SP. The anconeus flap transolecranon approach to the distal Humerus. J Orthop Trauma. 2006;20(4):282-5.

17. Ozer H, Solak S, Turanli S, Baltaci G, Colakoglu T, Bolukbasi $\mathrm{S}$. Intercondylar fractures of the distal humerus treated with the triceps-reflecting anconeus pedicle approach. Arch Orthop Trauma Surg. 2005;125:469-74.

18. Aslam N, Willet K. Functional outcome following internal fixation of Intraarticular fractures of the distal Humerus (AO type C). Acta Orthop Belg. 2004;70:118-22.

\section{JNMA $\mid$ VaL 49 Na. 2 ISSUE 178 APR-JUN, 2010}

